\title{
MALAYSIAN YOUTH SEXUALITY: ISSUES AND CHALLENGES
}

\author{
Low WY \\ Medical Education and Research Development Unit, Faculty of Medicine, University of Malaya, Kuala Lumpur
}

\begin{abstract}
:
Youth sexuality is a great concern for many. Sexual health issues facing our youths are: premarital sexual intercourse, sexually transmitted diseases, unwanted and unsafe pregnancies and abortions, sexual diversity, HIV/AIDS, and cybersex. Various factors lead to risky sexual and reproductive health behavior, particularly among those unmarried youths: lack of sexual and reproductive health information and skills in negotiating sexual relationships and the inaccessibility of youthfriendly sexual and reproductive health services. Growing peer pressure of pre-marital sex plays a major role in sexual and reproductive health related decision-making among youths. Another factor is the issue of sexuality education which is still considered a sensitive topic and thus impinging on its implementation, due to cultural and religious constraints. Misunderstanding and a lack of information on sexual diversity have caused a concern for many, as there is a tendency for judgments, stereotypes, discriminations and prejudices towards homosexuality in the society. Online sexual activities or cybersex have become the next sexual revolution. Negative consequences are shown for those hooked on cybersex. Healthy youths are fundamental to the prevention initiatives. Promoting the sexual and reproductive needs and rights of our youths is warranted. (JUMMEC 2009; 12 (1):3-14)
\end{abstract}

KEYWORDS: sexual knowledge, sexual attitude, sexual behaviour, adolescent, reproductive health, sexual health

\section{Introduction}

The World Health Organization (WHO) refers sexuality to a core dimension of being human which includes sex, gender, sexual and gender identity, sexual orientation, eroticism, emotional attachment/love, and reproduction. It is experienced or expressed in thoughts, fantasies, desires, beliefs, attitudes, values activities, practices, roles, relationships. Sexuality is a result of the interplay of biological, psychological, socio-economic, cultural, ethics and religions/spiritual factors.

Malaysia is experiencing a population age structure characterized by "population momentum," the "youth bulge" and the "demographic bonus." According to the WHO, "adolescence" is the period from 10 to 19 years and "youth" refers to those between 15 to 24 years old. The term "young people" covers those between 10 and 24 years old.

Sexual health of youths has emerged as an issue of great concern for many, particularly, the policy-makers, health service providers, family, community and the individuals him/herself. Trends in youth sexual and reproductive behavior are changing and health care professionals must be aware of these trends to provide necessary sexual and reproductive care and education to this population. The main sexual and reproductive health issues facing our youths are: premarital sexual intercourse, sexually transmitted diseases (STD), unwanted and unsafe pregnancies and abortions, HIV/AIDS, sexual diversity, cybersex and sexuality education.

\section{Sexual Knowledge, Attitudes and Behaviors of Adolescents and Youths}

There is a growing incidence of premarital sexual activity among youths, especially adolescents, owing to the widening gap between age at menarche

\footnotetext{
Correspondence:

Low Wah Yun

Medical Education and Research Development Unit Faculty of Medicine, University of Malaya

50603 Kuala Lumpur

Email: lowwy@um.edu.my
} 
and age at marriage. The continuing prevalence of premarital sexual activity and the low contraceptive usage, result in a high rate of adolescent and youth fertility. The consequences of these pregnancy and childbearing have significant effects on maternal and child health.

Motivations for premarital sexual activities are likely to be different for adolescent men and women. There is a gender difference in how youths perceived sex and their low perception of risk of contracting HIV and AIDS, and negative attitudes towards condom use. Sexually active young adolescents and youths need to understand the risks involved and that the risks apply to them. Due to the difference in the nature of pre-marital sexual activity between men and women, these young women often experience negative consequences of pre-marital sexual relations. As most acts of premarital sexual intercourse are unprotected, sexually active young men and women are increasingly at risk of contracting and transmitting STDs, including HIV and AIDS, subsequently leading to unwanted pregnancy and abortion.

There are various factors that lead to risky sexual and reproductive health behavior, particularly among those unmarried youths: lack of sexual and reproductive health information and skills in negotiating sexual relationships and the inaccessibility of youth friendly sexual and reproductive health services. Growing peer pressure of pre-marital sex plays a major role in sexual and reproductive health related decisionmaking among youths. Another factor is the issue of sexuality education which is still considered a sensitive topic due to cultural and religious constraints. A comprehensive school-based sexuality education that addresses the socio-cultural, biological and psychological and spiritual dimensions should be part of the HIV education programme in school and should be appropriate to the age, development level, and cultural background and respect the diversities of values and beliefs in the community.

In a study of 1,200 mostly single adolescents aged 15-21 years in the Kuala Lumpur city (1), knowledge on virginity, pregnancy, contraceptive methods were found to be low. Their sources of information were mainly from books, friends and parents, and there is an unmet need for such information. In the 1994/95 National Population and Family Development Board
(NPFDB) study, most times the adolescents did not discuss matters relating to reproductive health and sexuality with anyone except about puberty changes. When they did so, however, they preferred "friends", with "mothers" and "teachers" as second or third choices.

The level of knowledge does not appear to improve with time as another recent study involving older respondents (average age 22.61 years) in a major university in the Klang Valley showed that of the 114 medical (Year 4) and 81 nursing (Years 2 and 3) students and 85 students who registered for a Sexual Health Course, the average score was only 39.84 or $55.3 \%$ of the maximum of 72 (2). The students were assessed on their knowledge on physiological, psychological and social aspects of sexuality. Male students attained a higher level knowledge score than female students, with the lower scores contributed mainly by the nursing students and the score increasing with the age of the respondents. Medical students fared better than non-medical students scoring higher at $60.6 \%$.

\section{Dating Behavior}

In a study of 1,181 unmarried respondents interviewed, it was found that $44 \%$ of the respondents had ever dated (3). The incidence of the types of behavior engaged during dating varied between male and female respondents for "kissing and necking" (44.1\%), "petting" (35.3\%) and "sexual intercourse" (20.3\%) with males reporting a higher level than girls. Female respondents had a higher level of "no physical intimacy" compared to male respondents (3).

Another study on Youth Sexuality Survey (4) carried out by the Federation of Family Planning Association of Malaysia (FFPAM) of 1,303 respondents from 15 to 24 years in Peninsular Malaysia, i.e. Penang, Kelantan, Selangor/Federal Territory of Kuala Lumpur and Sarawak, found that dating behavior and pregnancy history differed between the 674 out-of-school youths, who were slightly older, and the 629 in-school/ college students. Most in-school students began dating from age 15 years reaching a peak rate at 18 years for both girls and boys, whereas for the out-ofschool youths, the first age for dating was reported at between 18 and 20 years. The majority of in-school females $(62.4 \%)$ had dated three or fewer males, while a-third had only dated one person, with a maximum 
record of 10 partners being reported by $4.7 \%$ of the respondents. For the in-school males, $56.6 \%$ of them had between one to three female partners, with slightly higher frequency for dates involving four to 10 partners being reported. More of the out-of-school females and male respondents had dated only one partner, at $40.4 \%$ and $23.7 \%$ respectively, and most of them had dated five or less partners.

One has to be cautious about the findings on dating behavior, considering the sensitivity of the questions asked on the various dating behavior. This becomes more apparent when the differential behaviour between boys and girls are noted. Boys tend to "claim" they have done many of these behaviors, while girls tend to "deny" them. The prevalence reported is not likely to be the pattern since these are reciprocal behaviors involving both sexes. The urban-rural difference and the age-specific pattern are as expected, with more urban and older youngsters involved more in each of these dating behaviors. The challenge to policy makers is obvious; if these behaviors are not to be sanctioned based on cultural/religious grounds, and yet there is evidence that young people are engaged in them, what is the most appropriate response? To disallow these behaviors would require a very arduous task of putting in place sanctions that are to be enforced and monitored, let alone assessing their consequences.

The findings on sexual behaviors revealed interesting, relevant, and challenging findings. Overall, there is an increasing trend in youth's sexual behavior. What is even more of a concern is that most of these sexual encounters are unsafe with no protection against unwanted pregnancy, STDs and HIV. The common assumption that "most, if not all births occur within marriage", may not be true. From anecdotal and media reports on incidences of abandoned babies, it is reasonable to postulate that many of these "unknown" age mothers are unmarried young women.

\section{Age of sexual initiation (sexual debut) and sexual activity}

Data on the age of first intercourse and incidence of sexual activity among adolescents varies between surveys, as shown in Table 1. Age at first intercourse (sexual debut) ranged from nine years to 24 years with a mode probably at 17-18 years. The percentage of young people who were sexually active ranged from slightly less than $1 \%$ among adolescents aged between 13 and 19 years who were interviewed in a household survey to $54 \%$ among in-mates (up to 30 years) in drug rehabilitation centers.

The NPFDB National Study on Reproductive Health of Adolescents reported only about 1\% (13 cases of 1,379 adolescents 13-19 years) who admitted that they had ever engaged in sexual intercourse. A Media Survey carried out to supplement the study, however, showed this rate to be $27 \%$. The vast difference could be attributed to the methodology of the study, in that for the former, the questionnaire was completed within the living quarters, and probably with an adult in the vicinity, whereas for the latter, the sample was self-selected and anonymous. The respondents from the Media Survey were also older (52.8\% were between 18-20 years) and from the urban areas (71.7\%).

The FFPAM Youth Sexuality Survey showed the age at first intercourse to be as early as 9-10 years for both male and female in-school respondents and female out-of-school respondents, while male out-of-school respondents reported a later age and wider range of 15-25 years on their sexual debut (4). The mode was about 18 years. In the majority of cases, the partner for the first sexual intercourse was a "date" or "steady girlfriend/boyfriend", but about $15 \%$ of in-school males and almost $27 \%$ of the out-of-school males reported their first sexual encounter was with a "prostitute." Of the out-of-school females, 10 of the 22 cases reported this person to be "stepfather", "rape", "conman" and "others" indicating some form of coercion (4).

The study on health risk behavior of adolescents in the National Health Morbidity Survey II carried out in 1996 involving 30,000 respondents in school showed the prevalence of sexual practice at $1.8 \%$. The study further reported that in such sexual experience, $63.2 \%$ were heterosexual, $19.9 \%$ were homosexual (gays more than lesbians, 13.7 against 6.2 ) and that $9.4 \%$ had sex with prostitutes. Male students were twice as likely to be involved compared to female students ( $2.5 \%$ against $1.2 \%$ ) and those in higher classes (schooling in Forms 4 and 5, i.e. aged between 17 and 18 years) had a higher prevalence than those younger (schooling in Remove class- Form 3, i.e. aged between 13 and 16 years) at $3.5 \%$ and $1.1 \%$ respectively. 
Table 1: Age at first intercourse and incidence of sexual activity among adolescents

\begin{tabular}{|c|c|c|c|}
\hline Title of Study & Respondents & Age at First Intercourse (Range) & Percent Sexually Active \\
\hline \multicolumn{4}{|l|}{$\begin{array}{l}\text { National Study on RH of Adolescents } \\
\text { 1994/95 (NPFDB, 1998) }\end{array}$} \\
\hline \multirow[t]{3}{*}{ Household Survey } & Male: 673 & $15-17$ & Ever had sex: 0.94 \\
\hline & Female: 706 & & (13 cases) \\
\hline & $\mathrm{N}=1,379$ & & \\
\hline \multirow[t]{3}{*}{ Media Survey } & Male: 1,242 & 16.4 & 27.2 \\
\hline & Female: 654 & & \\
\hline & $\mathrm{N}=1,896$ & & \\
\hline \multicolumn{4}{|l|}{$\begin{array}{l}\text { Report on Youth Sexuality Survey } \\
1994 \text { (Chiam, 1995) }\end{array}$} \\
\hline In-school & Male: 277 & Male: $10-21$ & Male: 11.2 \\
\hline \multirow{4}{*}{ Out-of--school } & Female: 352 & Female: 11-21 & Female: 14.5 \\
\hline & Male: 337 & Male: $15-25$ & Male: 27.0 \\
\hline & Female: 337 & Female: 9-24 & Female: 6.5 \\
\hline & $\mathrm{N}=1,303$ & & \\
\hline \multirow{5}{*}{$\begin{array}{l}\text { Sexual Activities of Malaysian } \\
\text { Adolescents (Zulkifli, 1995) }\end{array}$} & Male: 792 & n.a. & All respondents: 8.9 \\
\hline & Female: 408 & & Ever dated: 20.1 \\
\hline & $\mathrm{N} 1=1,200$ & & Male: 26 \\
\hline & $\mathrm{N} 2=1,181$ & & Female: 5 \\
\hline & (Unmarried) & & \\
\hline \multirow{2}{*}{$\begin{array}{l}\text { Study on "Adolescents and AIDS" } \\
\text { (Shamsuddin et al, 1996) }\end{array}$} & 3462 students & & Students: 6 \\
\hline & $\begin{array}{l}885 \text { youths in rehabilitation } \\
\text { centers }\end{array}$ & & In-mates: 54 \\
\hline \multirow{3}{*}{$\begin{array}{l}\text { Sexual Behaviour and HIV } \\
\text { Knowledge Among Dermatology } \\
\text { cum Genitourinary Clinic Attendees } \\
\text { (Choon et al, 1997) }\end{array}$} & & $\begin{array}{l}\text { Percent had Intercourse before } \\
\text { age of } 20 \text { years: }\end{array}$ & \\
\hline & & Males: 22.5 & \\
\hline & & Females: 30.9 & \\
\hline \multirow{4}{*}{$\begin{array}{l}\text { JOICFP Project: Baseline Survey } \\
\text { on SRH of Adolescents and Youth } \\
\text { (FFPAM, 2000) }\end{array}$} & School-based & & School-based \\
\hline & (15-17 years) & & 2 (2 cases) \\
\hline & Male: 50 & & \\
\hline & Female: 50 & & \\
\hline \multirow{3}{*}{$\begin{array}{l}\text { Sexual Practices in Malaysia (Zulkifli } \\
\& \text { Low, 2000) }\end{array}$} & Male: 242 & & All: 13 \\
\hline & Female: 225 & & Male: 18.2 \\
\hline & & & Female: 7.1 \\
\hline
\end{tabular}

Source: Narimah A, Ang ES, Low WY, Lee MHS, Mymoon A, Nik Rubiah NAR. Sexual and Reproductive Health of Adolescents and Youths in Malaysia: A Review of Literature and Project. WHO 2005

Of the total 1,181 unmarried respondents aged 1521 years old and among those who have dated, 20\% (105) or about $9 \%$ of the total adolescents, reported having had sexual intercourse, especially among the male respondents (93\%) (3). The proportion of unmarried adolescents who have experienced sexual intercourse had increased to about $13 \%$ in an another study involving 468 respondents as a sub-set of population of the Malaysian Health and Lifestyle Survey 1991 commissioned by the Ministry of Health (5). The male respondents reported a higher frequency at $18.2 \%$ compared to the female respondents at $7.1 \%$ and working respondents were five times more likely than those still in school to be sexually experienced. In the Malaysian Health and Lifestyle Survey in 1992, a total of 247 secondary students ( $97 \%$ single, $51 \%$ males) of the survey's 2270 respondents or $4 \%$ had had sex. No further analysis was available for this group.

In another recent study of 4,500 respondents in seven districts in Negri Sembilan, some $5.4 \%$ have had sexual intercourse, and the mean age at first sexual intercourse was 15 years old. Some $17.8 \%$ of the respondents reported they had been pregnant or had made his partner pregnant (6). 
The age of sexual debut with the mode of 17-18 years is probably not very different from other similar countries. The wide variance among the several studies again suggests a low level of reliability in getting the accurate responses since this is also influenced by social and cultural sensitivity. Like dating behavior, information on sexual debut is likely to be not very accurate. There were however, some consistency among the several studies conducted, except for those studies that were vastly inconsistent for apparent reasons (use of different age groups and methodology). This in itself is a significant finding. It shows that the method of obtaining information on matters related to sexual activity determines the reliability of response.

\section{Contraceptive Use and Safe/Unsafe Sex}

Use of contraceptives among the adolescent population varies. In the NPFDB Adolescent Study, one-fifth of the respondents have ever used the condoms (21.5\%), and lower rates for the other methods; i.e. pills (6.1\%), spermicides $(2.2 \%)$, intra-uterine devices $(1.3 \%)$, and injectables (1.1\%).

In the Youth Sexuality Survey, for those who have had sexual intercourse, when asked about "precautions to prevent pregnancy", 90\% (46 cases) of the in-school females admitted not taking any measures, whereas about 60 percent of the out-of-school females did so. On the other hand, for male respondents, about $30 \%$ of in-school and $15 \%$ of out-of-school did take precautions to prevent pregnancy (4).

In the Kuala Lumpur study by Zulkifli et al (5), only $37 \%$ of sexually active teenagers used any form of birth control, even though a majority of them know about birth control methods. By far the most common method used was the condom (51\%), followed by the oral contraceptive (18\%) and withdrawal (15\%). Among those who did not use any form of contraceptives, about half explained that sex was not much fun with contraceptives or they found contraceptives too difficult to use.

While a relatively large number of young people do have knowledge on family planning, they do not as a rule, practice contraception. This gap between knowledge and practice is explained by poor availability of such services, since by policy, contraception is not offered by the public sector to the unmarried. Young people, however, have the choice of using services from the private and non-government sector, but this too is not likely to be prevalent in view of the social sensitivity and religious sanction against sex outside of marriage.

\section{Abortion}

In the last 20 years, the rate of contraceptive use has remained unchanged. In 1994, 54\% of married women used contraceptives; in 2004, this dropped to $51 \%$ and only $33 \%$ used modern methods like the pill, IUD and condoms (7). In the 2004 National Demographic and Health Survey, it was found that many Malaysian women do not want more children, but are not using contraceptives. This is substantiated by the findings that $25 \%$ of married women said they did not want another baby, but were not using any kind of contraception due to fear of side effects or dissatisfaction with modern contraceptive methods.

Barrier methods, specifically condoms, are not common as a contraceptive method despite being easily accessible, affordable and relatively free of side-effects. Only about 10 percent of new family planning acceptors use condoms (8). The persistently low use of contraception clearly indicates the continuing problem of public perceptions about the safety of modern contraception and the inadequacy of family planning programmes and the media to accurately inform and reassure people.

There is indeed an unmet need for effective contraception among Malaysian women. Evidence, globally, shows that when contraceptive use is high, abortion rates are low (9). Malaysia's low contraceptive use rates and unmet contraceptive needs contribute to unwanted pregnancies and a higher demand for abortion.

At the same time, age of first marriage is increasing, and there are more young and unmarried people who are becoming pregnant. According to the National Population and Family Development Board, a survey among secondary school students showed that, although only $2.4 \%$ admitted to have had sex, $20.7 \%$ of the respondents said they know of friends who have had premarital sex, $21.2 \%$ know of friends who have had illegitimate pregnancies and $10 \%$ have 
friends who have undergone abortions (10). More unmarried women are having unwanted pregnancies. Sexually active young or unmarried people are not permitted by policy to obtain contraceptives from the government nor NGOs services from the national family programme, and they are excluded and discriminated against. Unwanted pregnancies due to rape and incest (violence against women) are also increasing in Malaysia. In 2006, there were 2,431 reports of rape compared to 1,479 in 2003 (statistics, Royal Malaysian Police). It is estimated globally that only $10 \%$ of all rape incidence are reported due to stigma and fear; as such, the incidence could be much higher. Emergency contraception is not widely known and abortion rights of raped women are not established. The rising incidence of abandoned babies is another indicator of unplanned and unwanted births.

A report in 2007 stated that one baby is abandoned every ten days in Kuala Lumpur (11). From 2001 to 2004, the Social Welfare Department recorded 315 cases of abandoned babies, while police statistics revealed about 100 cases a year (11). Clearly, there are still gaps in the provision of, or access to, reproductive health services, including unmet needs for contraception, emergency contraception and abortion.

Awareness of this legal proviso is limited among women and women's service providers (12). Hence, abortion services are not widely or openly offered and are not easily accessible. In fact, abortion remains shrouded in secrecy even for married women. Many mistakenly believe that abortion in Malaysia is illegal in all circumstances. A survey of reproductive health clients (13) found that $41 \%$ of the women did not know the legal conditions for abortion. This lack of knowledge is because the legality involved is minimally discussed in health, social welfare and women's crisis services. Also, there has been no public effort to educate women on its legal status, including provision of information in the media (14).

Based on the Ministry of Health Malaysia annual report 2006 (15), among the commonest causes of admissions to the Ministry of Health hospitals, the top two causes are normal delivery (14.9\%), and complications of pregnancy, childbirth and the puerperium (12.39\%). Abortions are included under the latter. Further, death in mothers which were ascribed to abortions numbered from 0-4 deaths per year (Confidential Enquiries into Maternal Deaths, 1996 to 2000).

Apart from statistics, a qualitative study on the understanding of needs, experiences and perspectives of abortion among 39 urban working class married women in Penang, Malaysia (16), found that women who seek termination of pregnancy experience abortion-related complications such as depression, missing work and losing their jobs. Further, the women talked about facing difficulties in getting an abortion or a ligation due to their doctor's personal beliefs or having to wait for doctor's decision or pressure from husbands who want them to be discharged fast. The women cannot decide and the health system does not allow women to have what they want.

In the interests of reproductive health and rights, women are entitled to safe abortion. Although surgical abortion is widely available in Malaysia, medical abortion, a safer alternative, is still unknown to many. The paucity of information on abortion is a major barrier to making any meaningful situational analysis. However, whether more information will lead to more meaningful intervention remains questionable, given the religious and cultural sanctions against abortion. Even though "hard" data is not available on rates of abortion, the realities through observations and anecdotal reports do suggest that the rate is not as low as some would expect it to be.

\section{Sexual Diversity/Sexual Orientation}

In the local context, the issue of sexual diversity remains a neglected area of research. Misunderstanding and a general lack of information in this area have caused it to be a concern for many.

A qualitative study was carried out in Klang Valley to explore the living environment and lived experiences of 25 non-heterosexual men (gays) and 35 nonheterosexual women (lesbians) (17). In addition, 17 key opinion leaders from various NGOs were interviewed individually. It is important to take note that the results are thus not generalizable to or representative of the entire non-heterosexual citizens in the country. Specific findings are highlighted here. 
The hostile environment in the country has prompted non-heterosexual citizens to acquire a more critical attitude in life, such as developing a culture of suspicion and a culture of questioning as a defense mechanism to protect themselves, their safe spaces and their interests. A majority of the participants voiced their discomfort with the tagging of the word "homosexuality" as it is a classification with reference to sexual behaviors, and has often been used to associate with certain diseases, such as, HIV/AIDS or some form of a deviant behavior. The participants refused to be associated with such a politically loaded tag. This label is problematic and inaccurate. Thus, the word "non-heterosexuality" was used.

The participants have been widely stigmatized, neglected and discriminated in society, thus rendering them invisible, hidden and marginalized. Their sexual practices and identities have been misconstrued as deviant and immoral. Some non-heterosexual citizens also faced physical abuse and violence from the general public, as well as from those in authority.

The invisibility of the non-heterosexual community could also be due to the denial in acknowledging the rights of existence of this population. The common accusation is that non heterosexualism is influenced by Western thinking and lifestyles. This is vigorously denied by some of the participants. Many of them cope by simply conforming to what is expected of them, while leading double lives. The issue of "coming out" is a consequence of fear of being stigmatized and discriminated, and thus pushed the non-heterosexual citizens into hiding and reinforced the comfort of staying in the closet. This leads to isolation, mental stress and affects their well-being.

Many non-heterosexual individuals experienced difficulty in "coming out" to their families because of fear of being ostracized by their loved ones. Discriminations by family range from trying to "change" their sexual identity, disowning them to causing physical abuse and violence. Some were forced to get married or to seek help from psychiatrists or psychologist. Some families are more accepting, whereas some can be violent towards the nonheterosexual citizens.

At the workplace, the participants are deprived of the freedom of expression in the workplace because of the fear of being found out, and, therefore, they are silent about their identity. Some were deprived of their promotion or job confirmation. "Coming out" to colleagues or their employers depends on a number of factors: the level of secrecy, level of confidence, selfesteem and comfortability with one's sexuality. It was strongly felt that an individual should be awarded for what one does and not for who one is based on one's sexuality.

Discriminations also exist in the healthcare sector. Health care providers would assume non-heterosexual individuals to adopt certain sexual practices and, hence, were at an increased or decreased risk of certain diseases. There is a lack of information and services pertaining to sexual healthcare and safe sex for non-heterosexual citizens. The judgmental attitude and insensitivity of some health care providers discourage non-heterosexual citizens from seeking healthcare services for their needs. The myth of equating HIV/AIDS and STDs with nonheterosexuality still widely permeates the public and private healthcare sectors. Such erroneous assumptions have resulted in insurance companies making it compulsory for policies holders to declare their sexuality as a pre-condition to insurance coverage and protection. Blood donation campaign drives have also been known to deny the participation of nonheterosexual citizen.

Non-heterosexual citizens are distancing themselves from faith due to stigmatization, as they are condemned as sinners. Thus, they experienced a conflict between their sexual orientation and their belief in God. There is a fear that religion having a strong stand against homosexuality might turn away some nonheterosexual persons, and it is not just a question of losing a religion, but of faith in God.

There is a need for safe spaces, and this is associated with the ability of the general environment to accommodate the sensitivities of non-heterosexual persons. Where society is unwilling to accommodate these needs, the need for safe space is felt more acutely.

This study concludes that there is a need for civil society organizations representing non-heterosexual citizens' interests. Capacity building such as advocacy training and empowerment for the non-heterosexual community is critically needed, especially sexual rights 
advocacy. Due to the discriminations, stigmatization, prejudices, abuses and violence faced by nonheterosexual citizens, it is important to endorse the right of this community to be recognized, protected and to lead a non-violent life. In view of the paucity of research in the area, further research via a multidimensional and a multidisciplinary approach is warranted.

\section{HIV/AIDS}

Since 1986, when the first HIV/AIDS cases were diagnosed, up to June 2008 , as many as 82,704 people have been diagnosed with HIV (18). The number of cases detected has increased steadily with the expansion of testing capabilities throughout the country and comprises in large part the results of routine testing of selected groups. At present, HIV/ AIDS is relatively confined to certain sub-groups of the population. However, there are fears that the situation could expand into a general epidemic in view of the current trend. The recent United Nations Millennium Development Goals report commended Malaysia on its good record towards success in achieving all MDG targets by 2015, except in halting and reversing the spread of HIV/AIDS (19).

The profile of reported HIV infections has remained consistent, i.e., are predominantly of substance abusers
(IDUs), male, 20-39 years of age, of Malay ethnicity and are heterosexual. The relatively young age-group affected implicates losses in human capital investments and productive resources.

Despite the preponderance of infected men, there is serious concern over the rising numbers of women infected with HIV. Women with HIV bear the added risk of vertical transmission to infants. In addition, although the present numbers and proportion are small, there also appears to be a rising trend in new HIV infections classified as MSM (men having sex with men) transmission.

As shown in Figure 1, the majority of infections are related to IDU. As testing, diagnoses and reporting improve over time, the proportion of infections classified under unknown causation has narrowed. Over the same period, the proportion of infections classified as heterosexual has risen.

Furthermore, the preponderance of IDUs among HIV infected persons in Malaysia is partly due to a reporting bias. Substance abusers are routinely tested for HIV when they opt for treatment and rehabilitation or when they enter the criminal justice system. Although the direct route of disease transmission among this group is most likely through infected needles or other objects involved in using

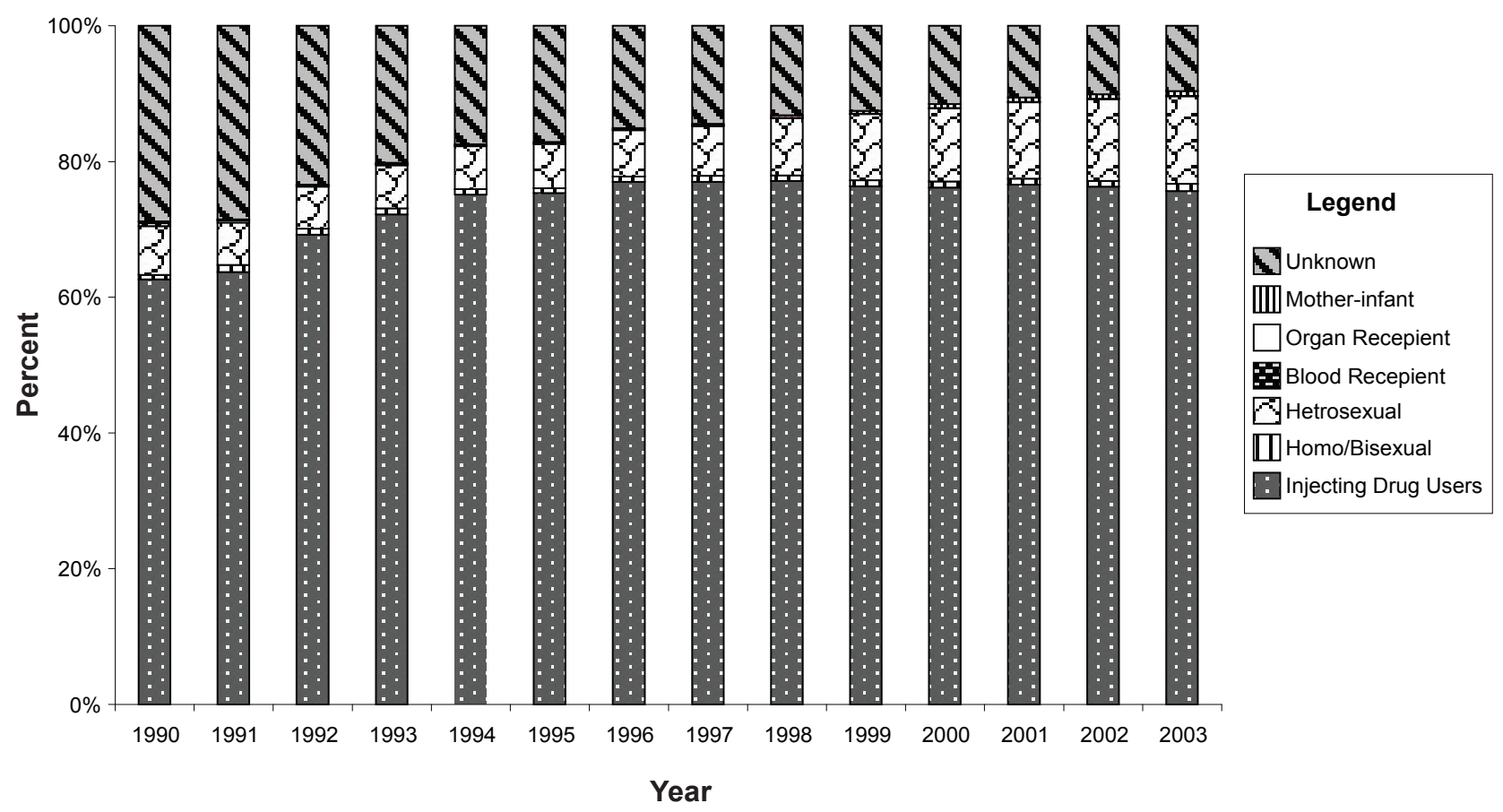

Figure 1: Percent cumulative HIV cases by year and mode of transmission 
intravenous drugs, it is recognized that unprotected sex may also be a risk factor. Most of the substance abusers are heterosexual and risk infecting their partners and offspring. Giving help to this group remains a priority in controlling the HIV epidemic.

While HIV cases have persisted to be overwhelmingly male, the percentage of women has increased from $1.4 \%$ in 1990 to 7,162 cases in June 2008. In terms of AIDS, the number of women diagnosed increased from two in 1991 to 1516 in June 2008, representing about $8 \%$ of all AIDS cases. Again, increased detection has followed expanded HIV testing among women through mandatory testing in antenatal care. The unequivocal difference between infections among men and women is because the large majority of women are infected through sex with an infected male partner, rather than through substance use. The number of HIV infected persons classified as housewives is similar to that of sex workers, a group considered high-risk. Entrenched gender inequalities and gender-based violence in its varied forms confer upon women unique vulnerabilities with regards to reproductive health problems, including HIV and AIDS $(20,21)$.

With regards to sexually transmitted HIV infections, heterosexual transmission predominates over other sexual routes, notably, men having sex with men
(MSM). In 2003, however, the number of HIV infections transmitted via bi-/homosexual activities nearly tripled from 51 cases to 151, a percentage that far exceeded increases in other modes of transmission. Although the percentage contribution of HIV cases attributed to MSM is relatively low at present, the potential for HIV to spread rapidly is a reality as there are opportunities for this to occur through many entertainment and recreational outlets for the MSM community, particularly, in urban centers. If estimates of the base population by sexual orientation were available, calculated rates of HIV infection within various subgroups could suggest a very different profile of risk.

Sexual routes of transmission also include infections among sex workers (SWs), both female, transgender as well as male SWs. The life circumstances and marginalisation of SWs necessitates specific prevention strategies.

Contrary to the widely held perception that sex workers are a high risk group, the available data shows that, by occupation, the majority of infected persons are categorized as long-distance drivers, followed by the unemployed or with temporary employment (odd job labour) and fishermen/fishmongers (Figure 2). A study on fishermen in Trengganu found an association between substance abuse and HIV infection among them (22).

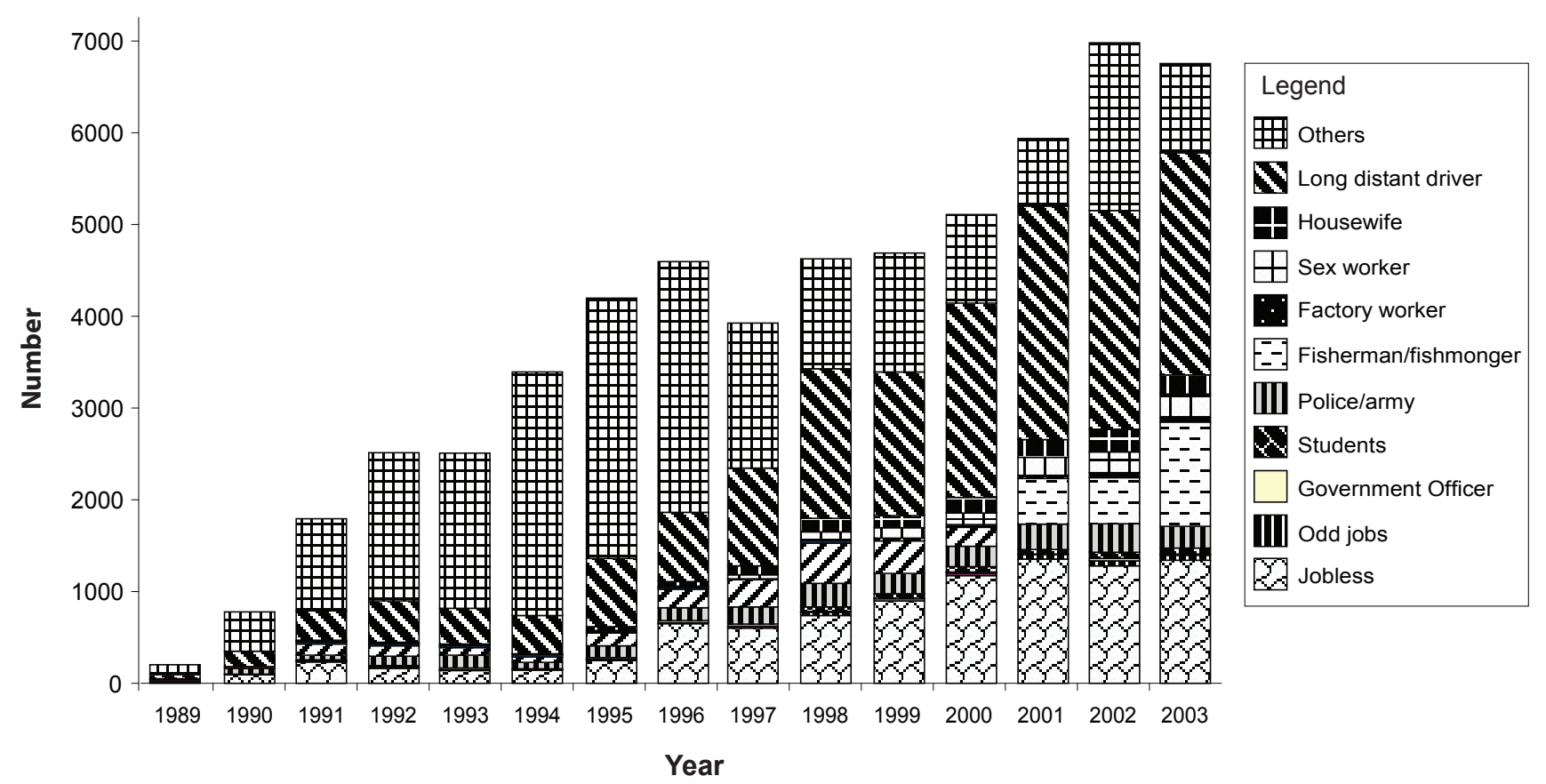

Figure 2: New HIV cases by year and occupation group 
While efforts to prevent new infections are of primary importance, the magnitude and growth of the HIVinfected population calls for due attention to the quality of life of those living with HIV (PLHIV). This involves an understanding of the multi-dimensional impact of HIV on the lives of the men and women infected with and affected by it and, in turn, enable more focused approaches to prevention.

A study was carried out to assess the impact of HIV on men and women living with HIV through a qualitative enquiry and provide evidence-based information on PLHIV, their families, and communities (23). Seven PLHIV groups, totaling 130 participants, consists of men infected through drug use, women infected by their partners/spouse, men who have sex with men, heterosexual men, women sex workers, transgender and refugees. This study was conducted in Kuala Lumpur, Selangor, Kota Baru, Kuching and Kota Kinabalu. Discussions among PLHIV focused on health, psychosocial and economic impact, experiences with stigmatization and discrimination, HIV-related services and resources. A summary of the findings are as follows.

Whilst there is now medical treatment for the physical health impact of HIV, there is insufficient attention to its psychological impact, especially for the newly diagnosed. The psychological impact arises in part from the economic impact and the stigmatization of PLHIV, including the associated burden of secrecy. There is clear evidence of stigmatization and discrimination of PLHIV from healthcare providers, employers, aid agencies, community and within the family. The stigma on HIV is rooted in the fear of contagion, including from casual contact, and moral judgments on associated behaviors. The fear of contagion has persisted, even for some in the healthcare profession, despite past Information, Education and Communication (IEC) campaigns, i.e., that HIV cannot be spread by casual contact, through sharing utensils, etc. NGOs and other HIV-related resources offer critical care and support to PLHIV, especially marginalized groups such as refugees, drug users, sex workers and transgender, and enabling their access to treatment, care and support, and to support prison inmates/residents after release to prevent transmission. Condom use is poor among men, even among clients of sex workers who may be exposed to higher risk of HIV and STIs. This resistance to condom use, despite awareness of potential exposure to STIs, involves a denial of risk and the lack of male responsibility.

Research is warranted to document and understand the impact of HIV over the short and long-term, how well PLHIV and their social support networks cope, what their needs are and how do these change over time. It is only with evidence-based findings that appropriate public health policies and programmes can be developed and adapted to integrate care, treatment and support services for PLHIV. Providing appropriate services enables the community living with HIV to live positively and fulfill their aspirations as individuals, members of families, community and Nation. This has positive implications for disease control and supports the National Strategic Plan on HIV/AIDS and the United Nations Millennium Goal to halt and reverse the spread of HIV.

\section{Cybersex}

The advent of the Internet has profound effects on youth's lives. Online sexual activities have become the next sexual revolution. The fact that the changing attitudes of today's youth has made cybersex palatable to the young net citizens. The American Psychological Association has demonstrated that those who do spend large amount of time in the Net in sexual pursuits may be at risk for developing psychological difficulties, eg. sexual compulsivity. It is also known to be a major contributing factor to separation and divorce of couples. Negative consequences are shown for those hooked on cybersex. Thus, understanding the common use of the Internet can help mental healthcare professionals develop guidance to prevent, diagnose, intervene and treat sexual compulsivity and related disorders. As Malaysia is highly wired, there is a need for research in this area as pornography and other forms of online sexuality activities is known to be rampant as reported in the media.

\section{Sexuality Education}

While there is no legal compulsion for the school system to include sexuality education, some commendable efforts are being or have been initiated in other aspects of education for adolescent health. The slow and uncertain uptake for sexuality education is due to the 
cultural and religious realities of the country. While the school system carries out formal education, there are also several efforts for informal education outside the school setting, carried out by both governmental and non-governmental agencies.

The Ministry of Education with its structured programmes such as Family Health Education (FHE) and co-curricular activities in schools, provides education and training to students to promote healthy lifestyle and responsible living. Sexuality education is named Family Health Education (FHE) in schools. Elements of FHE have been taught in secondary schools through Physical and Health Education, Science, Additional Science, Biology, Moral and Islamic Education since the implementation of the Integrated Secondary School Curriculum in 1989. Since 1994, elements of FHE have also been introduced to primary school children through Physical and Health Education. For Muslim students, sexual and reproductive health is taught in Islamic Education as a subject made compulsory in schools. It includes the internalization of Islamic values and good conducts as well as practices contained in the fardhu 'ain. These duties should be regarded as fundamental necessities and strong shield against the social ills in our society.

The Ministry of Education faces several challenges in reaching the desirable outcome and the objectives of sexuality education and Islamic Education. Admittedly, the increasing incidences of social ills and misconduct involving youths in recent times do not augur well in part for the success of sexuality education in the school curriculum. Monitoring efforts have revealed that teachers either shy away from the teaching this component or are themselves not skilled to deal with such sensitive subject. It is also not uncommon that sexuality education as a subject is given to teachers who are untrained in the area. Such situations are indeed opportunities lost because schools have all the resources and facilities to make educational programmes work.

It is beyond doubt that the school setting can serve as a highly significant resource for promoting adolescent health and development and for building gender equity, but, at present, from the evidence provided by the literature review, it is under utilized. However, several efforts towards adolescent health have begun by agencies, both in the government and non- government sectors. These are carried out through youth activities, the majority being community based, such as the PROSTAR, established in 1996, and conceived on the premise that it is "action by youth, through youth and for youth," aimed at enhancing "staying healthy without AIDS" within the framework of socio-cultural mores and religious values. Other programmes involved the Rakan Muda groups, and factory workers. Other agencies that are involved in developing and implementing training modules related to adolescent and youth health are National Population and Family Development Board, JAKIM (the Muslim Religious Council), Malaysian AIDS Council, FFPAM and other NGOs.

\section{Conclusions}

Increase capacity in youth sexual and reproductive health programme and service delivery is warranted. Understanding how youths make decisions to engage in early sexual activities is critical for intervention efforts aimed at fostering positive youth development and decreasing the negative outcomes of youth sexual behavior. Healthy youths are fundamental to the prevention initiatives. Promoting the sexual and reproductive needs and rights of youths are socially and politically sensitive topics. There has been a paucity of research in these issues. Hence, there is a lack of data on what strategies work best in different settings that can cater to young people's needs for information, life skills and services. Research in this area needs to incorporate multidisciplinary personnel to cater to the needs of our youths today.

Note: This paper was part of the Professorial Inaugural lecture delivered on 1st April 2009 by the author at the Faculty of Medicine, University of Malaya, Kuala Lumpur, Malaysia.

\section{References}

1. Low WY, Zulkifli SN, Yusof K. Knowledge and attitudes of Malaysian adolescents towards family planning. Sing J Obstet Gynaecol, 1994; 25(3): 279288.

2. Zulkifli SN, Low WY. Sexual practices in Malaysia: Determinants of sexual intercourse among 
unmarried youths. J Adoles Health. 2000; 27: 276280.

3. Zulkifli SN, Low WY, Yusof K. Sexual activities of Malaysian adolesecents. Med J Malaysia. 1995; 50(1): 4-10.

4. Chiam HK. Report on Youth Sexuality Survey. Malaysia, Selangor: Federation of Family Planning Associations; 1996.

5. Zulkifli SN, Low WY Sexual health education for youths - A Malaysian experience. Asia-Pacific J Publ Health. 2000; 12: S58-S66.

6. Lee LK, Chen PCY, Lee KK, Jagmohni K. Premarital sexual intercourse among adolescents in Malaysia: a cross-sectional Malaysian school survey. Singapore Med J. 2006; 47(6): 476-481.

7. Huang M. Prevention: Increasing contraceptive use. Paper presented at the Seminar on Reproductive Health, Rights and Miscarriages: Problems and Solutions, 3 July 2007, Negeri Sembilan, Malaysia.

8. Department of Statistics. Vital Statistics Report. Kuala Lumpur: Department of Statistics; 2003.

9. WHO. Adolescent pregnancy: Unmet needs and undone deeds. Unpublished review and literature and programmes.

10. National Population and Family Development Board. Report of the National Study on Reproductive Health and Sexuality 1994/1995. Kuala Lumpur: National Population and Family Development Board; 1998.

11. Ang ES. Adolescent health. Paper presented at the National Population Conference, 3-5 July 2007, Kuala Lumpur, Malaysia.

12. ARROW. Monitoring Ten years of ICPD Implementation. The Way Forward to 2015. Asian Country Reports. Kuala Lumpur: AsianPacific Resource and Research Centre for Women (ARROW), 2005.

13. Siti Fathilah K. Urban Malaysian women's experiences of abortion: Some implications for policy. Kajian Malaysia (J of Malaysian Studies). 1998; XVI (2): 53-77.
14 Rashidah A. Women's access to contraception and abortion - an urgent sexual and reproductive rights and women's human rights issue in Malaysia. Paper presented at the RRAAM Seminar on Speaking Out! Women's Rights to Contraception and Abortion. Petaling Jaya, Selangor, Malaysia. 1st March 2008.

15. Ministry of Health. Report on the Confidential Enquiries into Maternal Deaths in Malaysia, 19951996. Kuala Lumpur: Ministry of Health; 2000.

16. Wong YL, Aiyar S. Understanding women's needs, experiences and perspectives on abortion. Paper presented at the RRAAM Seminar on Speaking Out! Women's Rights to Contraception and Abortion. Petaling Jaya, Selangor, Malaysia. 1 March 2008.

17. Low WY, Ng CJ, Raymond T, Wong YM. Experiences of Non-Heterosexual persons in Klang Valley, Malaysia: An Explonatory Study. Ministry of Women, Family and Community Development, Malaysia, February 2006.

18. Ministry of Health (MOH) Malaysia. AIDs/STI Unit.

19. UNDP. Malaysia. Achieving the Millenium Development Goals. Successes and Challenges. The UN Country Team Malaysia and the Economic Planning Unit, Prime Minister's Department, Government of Malaysia. Kuala Lumpur: UN Country Team Malaysia; 2005.

20. Sen G, George A, Ostlin P. Engendering health equity: a review of research and policy. In: Sen G, George A and Ostlin P, eds. Engendering International Health: The Challenge of Equity. USA: Massachusettes Institute of Technology; 2002: $1-34$.

21. Heisse L, Ellsberg M, Gottemoeller M. Violence against women. Population Reports vol. L, no. 11. Baltimore: The John Hopkins University School of Public Health Population Information Program; 1999.

21. Ministry of Health Malaysia. HIV Infections among Fisherman in Trengganu. In: Malaysian Health 1999.

23. Zulkifli SN, Huang MSL, Low WY, Wong YL. Impact of HIV on People Living with HIV, Their Families and Community in Malaysia. Kuala Lumpur, Malaysia: United Nations Country Team, Malaysia; 2007. 